\section{Exploring the early stages of mineralization in the parietal and opercular plates of the barnacle Amphialanus amphitrite}

\author{
REBECCA A METZLER ${ }^{1}$, AMOGH GUPTA ${ }^{1}$, BEATRIZ \\ ORIHUELA $^{2}$, DANIEL RITTSCHOF ${ }^{2}$ AND GARY H. \\ DICKINSON $^{3}$ \\ ${ }^{1}$ Colgate University \\ ${ }^{2}$ Duke University Marine Laboratory \\ ${ }^{3}$ The College of New Jersey \\ Presenting Author: rmetzler@colgate.edu
}

Barnacles, such as Amphibalanus amphitrite studied here, are found worldwide throughout marine intertidal communities. As adults, Amphibalanus amphitrite have a calcified exoskeleton consisting of multiple plates: parietal or lateral plates surrounding the body, a base plate securing the barnacle to its substrate, and an operculum that opens and closes for feeding. Recent work found that Amphibalanus amphitrite begins the parietal plate mineralization process within 48-hours of metamorphosis [1]. Here, we use a combination of x-ray photoemission electron (X-PEEM) [2, 3], scanning electron (SEM), and confocal microscopies to provide an unprecedented view of the early stages of mineralization within the parietal and opercular plates. We show that 1-day after metamorphosis, the parietal and opercular plates have already begun the mineralization process, with both parietal and opercular plates consisting of small calcite crystallites of varied orientation. Figure 1 was produced for the parietal plates to highlight regions of high calcium concentration (Ca map), as indicated by bright pixels, and the orientation of the calcium carbonate crystals c'axes (PIC map), using the procedure outlined by Sun et al. [2] and GG Macros [3]. In comparison to the 1-day barnacle, the parietal and opercular plates of a 6-day post-metamorphosis barnacle appear to have larger co-oriented crystalline domains and, within the parietal plates, a thicker mineralized region. These results begin to provide hints to how mineralization progresses within the barnacle exoskeleton and provides a baseline for on-going experiments into how predicted changes in ocean temperature will impact the barnacle exoskeleton mineralization process.

[1] Metzler, O'Malley, Herrick, Christensen, Orihuela, Rittschoff \& Dickinson (2020), Royal Society Open Science 7

[2] Sun, Marcus, Frazier, Giuffre, Mass \& Gilbert (2017), ACS Nano 11, 6612-6622

[3] GG-Macros,

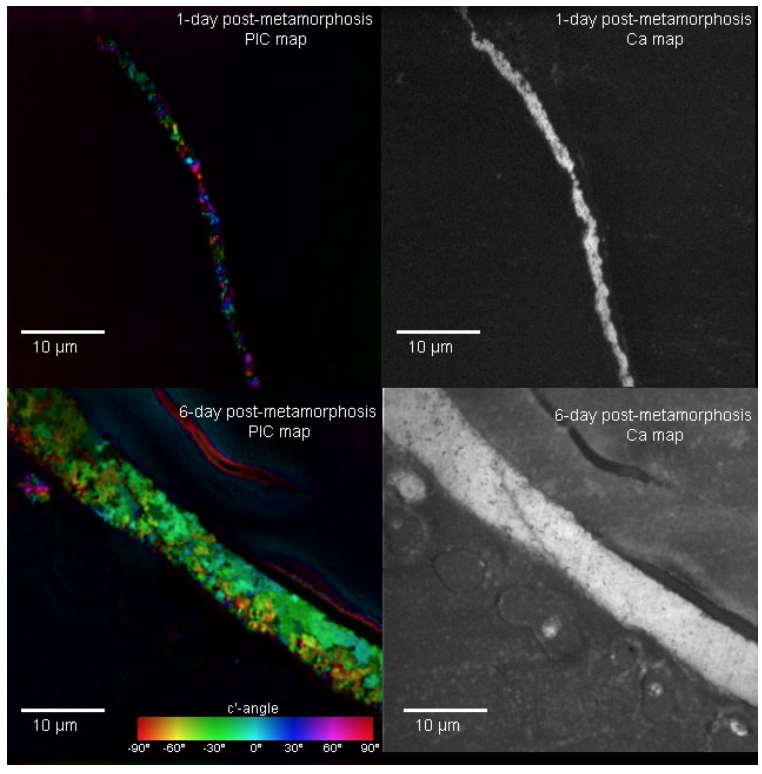

http://home.physics.wisc.edu/gilbert/software.html 